\title{
Rethinking of the Disciplinary Construction and Development of Foreign Languages at Colleges and Universities in the Background of "the Belt and Road Initiative"
}

\section{Dr. Hebin MA}

School of Foreign Language, Northwest Minzu University, Lanzhou, Gansu, P.R.China, 730030

Key Words: The Belt and Road Initiative; Foreign Language Disciplines; Construction; New Trend

\begin{abstract}
The Proposal of "the Belt and Road Initiative" has created an unprecedented historical opportunity for cross-border cultural exchanges. It's one of the important measures for China to promote the global governance system. Besides, it has new requirement for the disciplinary construction of foreign languages in colleges and universities in China. Therefore, the strengthening of construction and development of foreign language disciplines in higher education is an important way to help Chinese Culture enter the global arena.
\end{abstract}

\section{“一带一路”倡议下的高校外语学科建设与发展新思考}

\author{
马和斌 \\ 西北民族大学外国语学院, 兰州市, 甘肃省, 中国 \\ Email: alihb@126.com
}

关键词: “一带一路” 倡议; 外语学科; 建设; 新走向

中文摘要. “一带一路” 倡议建构了跨境人文交流前所未有的历史机遇, 是中国推动全球治理 体系的重要举措之一。“一带一路” 倡议为中国高校外语学科建设提出了新的要求。加强高 校外语学科建设与发展是服务中国文化走出去的重要途径。

\section{1. 引言}

中国官方外语教学历经多个艰辛发展时期, 业已积累了经验, 取得了成绩。基于当下国 际环境的深刻变化与国内社会的需求, 外语教学尤其是高校外语教育面临着前所未有的挑战。 重新确定学科建设, 科学设计专业方向, 合理配置课程类型, 建构国际化标准的培养目标, 组建前瞻性的教学团队, 建设服务取向的科研效应等问题, 不仅需要教育者认真思考并努力 付诸行动, 且各主导部门应综合考虑制订全面发展的科学政策。中国文化走出去、提升国家 文化软实力、“一带一路” 倡议及中国参与全球治理体系等诸要事, 缺少外语是不行的。

\section{2. “一带一路” 倡议构建跨境人文交流新机遇}

2013年9-10月, 中国提出共建“丝绸之路经济带”和“21世纪海上丝绸之路”的伟大战略倡议 （简称“一带一路”），旨在加强与沿线国家的“政策沟通、道路联通、贸易畅通、货币流通、 民心相通”。“一带一路”的互联互通构想, 旨在与沿线64个国家及多个区域性经济组织密切 
合作，发掘区域内市场潜力，促进投资和消费，创造需求和就业，增进沿线国家人文交流与 文明互鉴, 让各国人民相逢相知、互信互敬, 共享和谐、安宁、富裕地生活。2015年3月，《推 动共建丝绸之路经济带和 21 世纪海上丝绸之路的愿景与行动》正式发布, 标志着“一带一路” 倡议进入全面推进阶段。中国政府秉持和平合作、开放包容、互学互鉴、互利共赢的理念, 全方位推进沿线各国的政治互信、经济融合、文化包容的利益共同体、命运共同体和责任共 同体。其将以经济走廊理论 ${ }^{1}$ 、经济带理论 ${ }^{2}$ 、21世纪的国际合作理论等创新经济发展理论、 区域合作理论、全球化理论，给21世纪的国际合作带来新的理念。

两汉先辈开辟了以洛阳、长安为起点的联通东西方陆地贸易和文化交流的通道。唐僧人 玄牀（602-664）沿前辈开拓的丝绸之路行程13800公里赴印, 架起了中华文化与印度文明沟 通的桥梁。他游历印度19载, 著述12卷《大唐西域记》。回国后, 他又潜心翻译75部共 1335 卷佛典, 介绍佛教文化。

14世纪, 摩洛哥旅行家伊本·白图泰 (Ibn Bațutah, 1304-1377) 从家乡丹吉尔城 (Tangier) 出发, 一路朝东抵泉州、杭州, 行程75000英里, 实地考察记录中国社会, 留下了宝贵的资料。

15世纪，郑和（1371-1433）七下西洋（1405-1433），进一步加深了中国与阿拉伯伊斯 兰世界的了解与交往。郑和代表明朝出使西域, 不仅有经贸往来, 又实地考察西域社会; 他 还随团带回了不少朝贡明王朝的西域使节。其航海壮举从多层次多方位加深了华夏民众与阿 拉伯世界的交流，谱写中外人文交流的重要历史篇章。

2016年9月27日, 习近平主持中央政治局第35次集体学习, 就“二十国集团领导人峰会和 全球治理体系变革” 展开讨论。他强调, 要提高我国参与全球治理的能力, 着力增强规则制定 能力、议程设置能力、舆论宣传能力、统筹协调能力。参与全球治理需要一大批熟悉党和国 家方针政策、了解我国国情、具有全球视野、熟练运用外语、通晓国际规则、精通国际谈判 的专业人才。要加强全球治理人才队伍建设, 突破人才瓶颈, 做好人才储备, 为我国参与全 球治理提供有力人才支撑。

2016年10月22日，北京外国语大学成立“区域与全球治理体系高等研究院”。彭龙校长对 此表示, 北京外国语大学区域与全球治理高等研究院是新形势下北外深化综合改革的 重要探索, 是对中央稳步推进 “一带一路”建设合作的积极响应, 是落实中央和国务院 统筹推进世界一流大学和一流学科建设的切实举措。北京外国语大学区域与全球治理 高等研究院定位为集教学、科研、智库资政为一体的研究型机构。高等研究院的工作 将围绕4个目标展开: 服务国家“走出去”战略、推动学科协同和学术创新、加强高端人 才培养、发行或出版研究报告和学术论著。国家全球治理体系总思路, 是“一带一路”倡议 的又一重大举措。为适应和服务该战略, 要培养大批具有国际规则制定及宣传、协调与统筹 考虑全球事物等方面相关能力的特殊专业人才。诸多专业人才要熟悉党和国家的方针政策, 了解中国国情及对象国国情, 能熟练应用外国语, 并通晓国际和区域规则, 精通国际商务与 外交谈判, 以国际视野在具体工作中切实完成任务。

中国高校的外语教育曾凸显专业化精英教育模式, 具有历史性特质的该种教育模式与当 下需求通识教育的宗旨有一定差异。基于“一带一路”倡议愿景, 国家提出全球治理体系的宏 远规划, 将未来人才培养提升至国际化复合型人才的高度, 建立国际化视野, 知已一一熟知 中国基本国情与党政基本方针, 知彼一一熟练应用外语、通晓国际或地区社会、精通国际谈 判技能与方略, 抑或是国内高校外语教育的风向标和外语学科建设及发展的新机遇。

(1) 中俄蒙经济走廊、新亚欧大陆桥、中国一中亚经济走廊、孟中印缅经济走廊、中国一中南半岛经济走廊等。

(2) 有别于历史上出现的各类经济带或经济联盟, 具有 “灵活性、适用性和可操作性” 之特点, 各国可平等自由参与, 协商推进。 


\section{3. 中国外语教育历程回顾}

中国外语人才的需求自秦汉肇始至今已有两年余年。据文史资料记载显示，“最早的（官 办）外国语文学校算是元代的“回回国子学””。“回回国子学”是元官方国子监之一, 建于至元 二十六年（1289）夏五月, 教授“亦思替非”文字。其位居蒙古国子监、国子监之后。其准入 条件是“凡公卿大夫与夫富民之子, 皆依汉人入学之制, 日肄习之。”可见, 能入回回国子监 者都是有社会地位的各族人士, 日后可委以重任, 效力朝廷。伊朗学者穆札法尔.巴赫蒂亚尔 认为，亦思替非文字“是古波斯人创造的一种特有的文字符号系统及计算方法，用以书写政府 税收事项。”回回国子监的出现和与暂短运行 ${ }^{1}$, 似乎可从一个侧面说明元时中国与西域诸国 的经济交往规模和程度已达到相当程度。

唐宋时, 侨居广州、泉州的蕃客在清真寺内兴办“蕃学”。该类学堂与官办学校略有差异, 主要教授诵读《古兰经》, 学习阿拉伯文书法、语法、历史和算学等。明时, 胡登洲 (1522-1597) 秉承蕃学精神, 结合传统私塾教育的特点创建了具有中国特点的民间教育体系——经堂教育, 以清真寺为教育场所, 培养外语 (阿拉伯语和波斯语) 、伊斯兰教学科、儒学等方面均有一 定造诣的专业人才。胡氏创建的经堂教育体系, 曾为中国培养不少精通儒学及伊斯兰学科的 世界级人才, 如刘智（约1662-1745）、马注（1640-1711）、马德新（1794-1874）、马联元 (1840-1903) 等。中国民间的外语教育已有400余年的历史。

《中国外语教育史》记载: 1708年, 清政府开设俄罗斯文馆，同年正式授课。而154年后， 其被并入中国近代正规外语教学摇篮的京师同文馆。创建京师同文馆伊始, 便设置英文馆; 次年增设法文馆和俄文馆; 1872年又设德文馆; 日语教学则始于1896年成立的东方馆。京师 同文馆的外语授课方式与洋务运动及清政府的外交活动日益频繁有一定关系。鸦片战争前, 西方传教士开办的“教会学校”在清政府“关照”下得到逐步发展, 后成为齐鲁大学、岭南大学、 金陵大学、东吴大学、燕京大学等高校创建的基础。

民国时期, 各地高校均设外国语言文学系, 培养外国文学教学和研究人员。其中，除开 设语言基本技能课程外, 文学及文学史是最常见的专业基础课程。1922年10月上海大学成立, 5 年内共招收 1800 余名学生, 其中部分学生被送往莫斯科中山大学深造, 为党培养了不少人才 及社会知名人士。1925年，马松亭（1892-1995）、唐柯三（1882-1950）等知名人士在济南 创建成达师范学校, 培养具有现代理念的三长（校长、教长和会长）。1929年秋, 该校迁至 北平 (现北京)。为使学生的学识结构更符合现代社会需求, 成达师范学校常邀请顾颕刚 （1893-1980）、冯友兰（1895-1990）、张星烺（1889-1951）、白寿彝（1909-2000）等学界 名流给学生做报告。1928年春, 中国回教学会在沪创办上海伊斯兰师范学校。上海福佑路清 真寺教长达浦生（1874-1965）兼任校长，哈德成（1888-1943）、买俊三（1888-1967）等担 任主讲教师; 该学校曾聘埃及亚历山大大学的穆罕默德.卡米莱 (Muhammad Kamil) 和印 度籍埃及学者法杜里·伊拉希 (Fadul Allha) 为外教。该校课程设置注重“四文”（即中文、阿 拉伯文、波斯文和英文) 教育, 并设置数学、地理、历史、教育学、政治学、哲学、体育等 课程。1931年, 该校开始有计划地向埃及爱资哈尔大学（Al-Azhar University）输送优秀青 年, 为新中国社会主义建设与阿拉伯语专业人才的培养做足了前期的储备。民国时期国内民 办的成达师范学校、上海伊斯兰师范学校等, 其“教育模式和方法、教材改进、人才培养等方 面”也最有成就; 培养的人才中的一些人曾赴埃及留学深造, 学成回国后成为中国高校阿拉伯 语专业的奠基者和开拓者。

(1)其始于至元二十六年（1289），延祐七年（1320）四月被罢。该外语教育机构在历史上仅存31年。

(2) 该校是突尼斯的宰桐大学 (Ez-Zitouna University,737) , 摩洛哥的卡鲁因大学 (University of Al-Karaouine, 859) 后 建立的第 3 所大学。始建于 972 年, 是埃及最古老的高等宗教学府。现在, 爱资哈尔大学采用现代化教学方法, 培养各类综 合性人才。现有在校学生 12 万人, 其中有来自 75 个国家的 1.2 万名留学生; 教职工 19000 人, 其中教师 6000 人; 全校有 36 个独立学院。该校比欧洲的博罗尼亚大学 (University of Bologna, 1088)、牛津大学 (University of Oxford, 1167)，剑 桥大学 (University of Cambridge, 1209) 等都早。 
抗战时期, 延安大学俄语系和延安外国语学校培养的学生, 在新中国成立后担负着外交、 对外宣传、外语教学等领域的核心工作。今日的北京外国语大学、黑龙江大学均是在延安大 学俄语系和延安外国语学校基础上发展起来的重点大学。其教育成果斐然。

20世纪五十年代, 中国外语教学的主体是俄语; 英、德、法等语种也有缓慢发展。六十 年代, 中国的外语教学得到了前所未有的重视; 如阿拉伯语和西班牙语教学出现了新中国历 史上第一次高潮。彼时, 教育部开始筹办外国语学校, 新建或扩建外国语学院, 加大招生, 加强外语学院或外语系办学条件, 启动派出留学人员 ${ }^{\circledR}$ 的语言培训工作。据统计, 截至1966 年3月，全国高等外语院系共开设41种外语; 其中开设英语的学校有74所。

“文革”时期，中国的外语教育基本处于停滞甚至萎缩状态。改革开放以来，中国的外语 教育出现了新的生机。国内外环境的变化与需求迫使外语教育需要进行重大改革; 从培养规 模、目标、层次与模式等方面都做了新的建构, 以适应社会改革的需要。培养模式从原来的 单一化走向跳跃式弹性化; 培养方向由语言类学科转向以外语为主的复合型; 多层次的培养 体系基本形成。像北京外国语大学、上海外国语大学及广东外语外贸大学的办学理念也发生 了较大的转变, 逐步朝着高层次、复合型、国际化的标准前行。进入 21 世纪, 中国外语教育 的理念又向“通识型”和“创新型”目标迈进。国内各高校，从外语专业课程大纲入手，以期逐 步达到拓宽专业学习领域, 实现专业教育和通识教育的有效结合, 培养学生的参与能力和创 新能力。

戴炜栋认为, 目前国内高校教授的外语语种已超过50个。每个语种的教学点大量增加, 如开设英语专业的高校达1000所。全国有1115所高校开设其他外语专业, 其中开设日语专业 的高校 400 多所, 开设俄语专业的高校 100 多所, 有 80 多所高校开设法语专业, 开设西班牙语 专业的也有 50 多所。作为高校外语学科重要组成部分的非通用语种,进入新世纪后也获得了跨 越式发展, 教学点布局不断拓展, 目前已在全国建立了9个非通用语种本科教学基地。国内以外 语为背景的外国语言文学专业硕士、博士学位授予点也大幅增加。目前, 全国的英国语言文 学硕士点已达到200多个, 外国语言文学博士点(包括外国语言学及应用语言学) 已有40余个。 目前中国高校外语教育环境喜人。

\section{4. 当下中国外语学科建设新思考}

新中国成立至今, 高校外语教育经历了复杂曲折的变革, 取得了令人瞩目的成就。经过 数代外语人的不解努力, 高校外语教学内容丰富, 结构科学, 方向明确, 为国家培养了数以 万计的各类人才。但权威人士调查研究后认为, 目前国内外语学科师资队伍出现“青黄不接” 的现象, 欠缺具有国际视野、能够把握学科前沿发展方向且具有团队协作能力的领军人才; 部 分院校对复合型外语人才培养目标把握不够准确, 存在专业知识课程设置不够规范和相关复 合型专业课时所占比重过大等突出问题; 我国高等学校外语教育还存在地区差异不断加大、 部分外语院校学生语言基本功不够扎实的问题, 相当一批院校特别是经济欠发达地区院校英 语专业的学生在语言技能上没有达到大纲的要求, 语言基础薄弱, 缺乏用英语连贯表达思想 的能力, 特别是英语写作和口语应用能力较弱。而造成这些问题的深层次原因在于高校外语 学科发展中长久以来存在的一些制约因素。以英语专业为例, 学生从小学到大学的 10 余年间, 都会把英语课当作学习的主要目标, 埋头苦读, 学习效果并不尽人意。而法语、德语、阿拉 伯语、俄语等通用语种使用面较小的语言专业主要在大学开设, 本科制4年。由于那些专业学 生还要研修其他课程, 专业课程的学习时间并不多。上述情况是学业与学习时间之间形成的 矛盾。另外, 因高校所处地域、教学者和管理者对外语认知的差异, 中国发达地区和欠发达 地区高校外语教育的效果迥然不同。鉴于这些实际情况, 教育部外语教学指导委员会曾花费

(1) 近代中国人赴海外 (美国) 留学始于 1872 年 8 月 11 日。1896-1906 年间, 有人赴日留学。1919 年, 有志者赴欧洲 (法国等) 留学。1921 年, 革命党人前往苏联留学。1933 年, 国民政府颁布《国外留学规程》, 确定留学条件、考试择优 派送等制度, 使个人留学行为变成国家行为。 
了很大精力, 通过各种有效途径敦促欠发达地区高校依据外语教育的标准进行教学和研究, 已取得了一定成效。

当下，国家“一带一路”倡议和全球治理体系方略为高校外语教学确定了新的目标。要“讲 好中国故事”, 将中国剩余产能输出到其他国家, 让中国好声音在国际舞台上产生回响, 均离 不开外语。“中国文化走出去, 外语学科大有作为。”为此有学者呼吁, 中国高校外语教育须 与国家战略同步, 方能使其学科建设与发展迈开更大的步伐, 产出更佳的成果。对此, 笔者 斗胆提出如下建议, 恳请与识家商讨。

\section{1. 外语学科建设是提升国家软实力的重要支撑}

“文化作为一种软实力, 其推介不仅有助于增强不同国家间的认同与互信, 而且有助于 提升我们的国际影响力。无论合作涉及贸易、金融领域, 还是科技、教育领域, 均需要高层 次的国际化外语人才, 如致力于高层次学术交流与推介的外语学术研究人才以及大批具有国 际视野、通晓国际规则、能够参与国际事务和国际竞争的多语种跨文化人才, 而外语学科是 培养此类人才的重要渠道。” 中国传统文化走出去, 实质上需要高级外语翻译人才把中国传 统文化讲给他人听 ${ }^{1}$, 讲好 “中国故事” , 且还需要对中国传统文化有一定建树的高级研究者; 有能力承担国际学术会议的同传任务、国际组织中担任相关工作的优秀人才, 跨国金融和司 法专业人才。在 “文化走出去” 背景下, 外语学科有必要适应国家和地区对人才的需求, 结 合所在院校特色, 规划各类人才培养项目, 推行双向国际化理念, 培养具有国际视野的多元 跨文化人才。中国的外语工作者和高校教师, 除精通外语知识外, 还需具有扎实的中国文化 基础，才能在国际学术界和高校讲坛上驾驭自己的话语权，才能做好对外宣传。

\section{2. 制定适合国家战略需求的外语中长期发展规划}

2010年5月, 《国家中长期教育改革和发展规划纲要 (2010-2020) 》( 以下简称《纲要》) 发布, 明确指出 “提高高等教育质量, 提高人才培养质量, 优化教育结构办出特色, 加快建 设一流大学和一流学科。”国家教育发展规划是高校教育发展的指南, 是国家战略的重要组 成部分之一。高校须制订与国家战略相匹配的外语教育中长期发展规划, 才能使外语专业的 发展有计划有步骤的实施, 为建设一流学科和一流大学做应有的积淀。就高校个体而言, 依 据各自特点确定外语专业定位, 制订外语专业发展规划是学校提高教育质量与人才培养质量 的保障之一。

高校外语教育不仅只是为了满足国家、社会和学生个体的当前需求, 还要着眼未来需求。 高校外语教学可以参照《纲要》, 根据外语教育国情, 结合国家相关教育方针政策, 制定出 相应的大学外语教育规划纲要。这样才能立足长远, 培养出当前及未来很长时期内能够学以 致用、持续发展、胜任竞争的外语人才。国内学者认为, 高校外语教育是 “国家外语能力” 输出的端口, 有义务和责任为国家需要的外语能力确定相应的外语教育规划。高校外语教育 的目标应该是培养大学生用外语直接从事专业学习和研究, 以便使其能够在自己的学科领域 内获得较强的国际交流能力和竞争力, 最大限度地发挥外语的工具作用。推动 “一带一路” 倡议过程中, “语言不仅会通中外思想, 超越文化藩篱, 推动文明创新, 是促进人文交流, 实现民心相通的根本保障，也是服务互联互通建设的重要支撑。”

中国高校外语教育已走过了半个多世纪的历程, 教育成效令人瞩目, 但也有不足; 尤其 是外语教育属性的确定。一段时间里, 全民把学习外语当作一项任务 (工具) 去完成, 而当 下学习外语者考虑的则是如何通过考试以获取某个资质; 类似的窘困或多或少地干扰着外语

(1) 诸如积极参与 “经典中国国际出版工程”、“中国图书对外推广计划”、“中国文化著作对外翻译出版工程”、“中 华学术外译项目” 等。 
教育的规划。基于全球化大背景与 “一带一路” 倡议, 中国高校教育 “必须把外语当作学习 语言转变为学生专业服务”，才能适应国家战略发展需要。

外语教育的基本要求至少应该达到语言基本技能的标准, 在此基础上可做适合自己特点 与愿望的补充, 使外语教育朝着复合型或人文学科的方向发展。国内各高校（特别是外语专 业建设期较短的高校) 应依据各自外语教学的传统与特点, 从宏观上制订专业学科规划, 且 需从实际出发在专业发展过程中做微观调节, 在 “以人为本、个性化” 现代教育理念下进行 专业教学。

\section{3. 储备具有国际视野的教学科研团队}

学者研究国内外语教学现状时说: “专业已在很大程度上被市场化、低端化、工具化所 绑架（有的可能是自愿的, 甚至是主动的）, 前景堪忧。” 该评价并非空穴来风, 而是基于 对国内高校外语教育的实地考察认真研究后给出的答案。究其原因很多, 除专业规划执行不 到位、外语教学理论研究薄弱、评估和管理缺乏科学和有效的标准外, 师资质量恐怕是国内 高校外语教育发展的最大问题。高校外语专业教师应具备 4 个基本条件：语言基本功（外语和 母语）, 教学技能, 专业知识, 研究能力。要想成为一名合格的外语教师, 上述 4 个基本素养 缺一不可。但由于高校教育环境的差异, 有些高校里 “忙于教学的教师根本没有充裕的时间 去准备自己的教学, 他们往往只是在应付学生和学校的任务, 更不用说去阅读学术著述和撰 写论文了。” 清华大学王宁教授一针见血地指出, “如果他们不努力去提高自身的水平, 课 上的越多其危害性就越大!

培养大批具有国际视野、通晓国际规则、能够参与国际事务和国际竞争的国际化人才， 是国家中长期教育发展规划的总纲领。要实现其中的各项指标, 国际化外语人才的培养是必 不可少的。教师是高校人才培养的主导。一个或多个具有国际化视野的专业教师团队, 会影 响受教育者的研究兴趣和研究方向, 带领学生朝着学术研究的国际化迈进。只有如此, 才能 更多地培养高端外语人才 (翻译、外事、国别研究等), 甚至 “中国语言文化海外传播人才”。 高校国际化视野教师教学科研团队的建设与发展, 应立足国内面向世界; 学术研究亦应如此。 高校外语教师除做好本职的教学和科研工作外, 还应有参与国家战略需求的工作, 用外语把 中国故事讲好。“除了要学好母语用中文在国内发表著述外, 更要重视提高自身英语的写作 和中译英的水平，这样才有资格参与到中国文化走出去的大项目中。

\section{4. 主动服务国家战略, 促进学科发展}

中国高校外语教育曾以 “内向型” 服务为主, 立足国家现代化建设。而在 “一带一路” 建设中, 我们需要更多精通沿线国家语言的高层次外语人才, 需要更多熟悉 “一带一路” 国 别乃至区域研究的人才, 需要更多语言能力过硬、具有国际视野、能进行有效跨文化沟通的 行业专才。为此, 当下高校外语教育应适应 “外向型” 战略的需要, 继续秉承已有的外语教 育理念与传统, 借鉴国外外语教育经验, 确定具有中国特色的外语教育新模式, 在教育对象、 教育阶段、教育目标中逐步探索出新的思路, 主动为国家战略服务, 在外语专业、跨国别与 区域研究方面探索出新方法, 促进外语学科的进一步发展。

\section{致谢}

本文为西北民族大学2017年研究生课程教育改革项目 “基于研究生课程教育改革的科研 创新能力培养模式研究——以《阿拉伯文化语言学》为例”的阶段性成果之一。 


\section{References}

[1] Xi Jin-Ping. Participation in global governance need to be proficient professionals in international negotiations. [EOL]. Please see: http://news.sina.com.cn/gov/xlxw/2016-09-29/doc-ifxwkzyh3818346.shtml

[2] The founding ceremony of the Institute of Regional and Global Governance of Beijing Foreign Studies University was held in Beijing[EOL]. 2016-10-22, http://www.cssn.cn/zx/bwyc/201610/t20161022_3245566.shtml

[3] Li Chuan-Song, Xu Bao-Fa. A History of Modern Foreign Language Education in China [M].Shanghai: Shanghai Foreign Language Education Press,P.1,PP.2-21,2006.

[4] Wang Jian-Jun. Study on the Imperial College of Huihui in Yuan Dynasty[J]. Journal of Hui Muslim Minority Studies,PP.37-38,Vol.1,2004.

[5] Qiu Shu-Sen ed. China Hui Nationality History(Vol.1) [M].Yinchuan: Ningxia people's Publishing House,pp.106-107,1996.

[6] Fu Ke. A History of Foreign Language Education in China [M].Shanghai: Shanghai Foreign Language Education Press,P.11,1986.

[7] Dai Wei-Dong, Hu Wen-Zhong ed. Study on the Development of Foreign Language Education in China (1949-2009) [M]. Shanghai: Shanghai Foreign Language Education Press,P.3,2009.

[8] Ding jun. A History of Arabic Language Education in China[M].Beijing: China social sciences press,p.42,2006.

[9] Wen Qiu-Fang,Xu Hao eds. 2013 Annual Report on China Foreign Language Education[R].Beijing: Foreign Language Teaching and Research Press,p.37,2014.

[10] Dai Wei-dong, Wu Fei. On the development of foreign language studies in China:Constraints and strategies[J].Journal of Foreign Language Teaching and Research,Vol.3,PP.171-173.2010.

[11] Dai Wei-Dong. A Report of Foreign Language Major Education Development at Colleges \& Universities in China (1978-2008)[R].Shanghai: Shanghai Foreign Language Education Press,P.21,2008.

[12] Wang Ning. Chinese culture goes global: a great accomplishment in foreign languages[J].Journal of China Foreign Languages, Vol.2,pp.10-12,2013.

[13] Dai Wei-Dong, Wang Xue-Mei. The Developmental Strategies of the Discipline of Foreign Languages and Literature under the Background of Chinese Culture Diffusion[J]. Journal of PLA University of Foreign Languages, Vol.4,p.3,4.2015.

[14] Ding Ren-Lun, Dai Wei-Dong.Think on the orientation of college foreign language teaching[J].Journal Foreign Languge World,Vol.2,p.21,2015.

[15] Cai Ji-Gang, Liao Lei-Chao.National Requiremants for Foreign Language Capacity and College Foreign Language Education Planning[J]. Journal of Yunnan Normal University (Philosophy and Social Sciences Edition),Vol.1, pp.15-16, 2014.

[16] Shen Qi. Strategic Transformation for the construction of our natonal foreign language competence under the guidance of the strategy of One Belt and One Road[J]. Journal of Yunnan Normal University(Philosophy and Social Sciences Edition),Vol.5, p.9, 2015.

[17] Shu Ding-Fang. Three Approaches to Reviving English as a Major in Chinese Universities[J]. Journal of China Foreign Languages, Vol.5,p.5,2015.

[18] Sheng qi. Obligation and Missions of Foreign Language Discipline: On Professor Xu Guozhang`s Tribute to Foreign Language`s Edcation[J].Journal of Mornden Foreign Language Studies, Vol.11,p.13,2015. 